\title{
Two susceptible HLA-DRB1 alleles for multiple sclerosis differentially regulate anti-JC virus antibody serostatus along with fingolimod
}

Mitsuru Watanabe ${ }^{1 \dagger}$, Yuri Nakamura ${ }^{1,2,3 \dagger}$, Noriko Isobe ${ }^{1,4}$, Masami Tanaka ${ }^{5,6}$, Ayako Sakoda ${ }^{1,2}$, Fumie Hayashi ${ }^{1}$, Yuji Kawano ${ }^{1,7}$, Ryo Yamasaki ${ }^{1}$, Takuya Matsushita ${ }^{1}$ and Jun-ichi Kira ${ }^{1,2,8^{*}}$

\begin{abstract}
Background: Progressive multifocal leukoencephalopathy (PML) caused by JC virus (JCV) is a rare but serious complication of some disease-modifying drugs used to treat multiple sclerosis (MS). Japanese MS patients treated with fingolimod were reported to be 10 times more likely to develop PML than equivalent patients in other countries. The strongest susceptibility human leukocyte antigen (HLA) class II alleles for MS are distinct between races (DRB1*15:01 for Caucasians and DRB1*04:05 and DRB1*15:01 for Japanese); therefore, we investigated whether HLA class II alleles modulate anti-JCV antibody serostatus in Japanese MS patients with and without fingolimod.

Methods: We enrolled 128 Japanese patients with MS, in whom 64 (50\%) were under fingolimod treatment at sampling, and examined the relationship between HLA class II alleles and anti-JCV antibody serostatus. Serum anti-JCV antibody positivity and index were measured using a second-generation two-step assay and HLA-DRB1 and -DPB1 alleles were genotyped.

Results: HLA-DRB1*15 carriers had a lower frequency of anti-JCV antibody positivity (57\% vs 78\%, $p=0.015$ ), and lower antibody index (median 0.42 vs $1.97, p=0.037$ ) than non-carriers. Among patients without HLA-DRB1*15, $D R B 1 * 04$ carriers had a higher seropositivity rate than non-carriers ( $84 \%$ vs $54 \%, p=0.030$ ), and $D P B 1 * 04: 02$ carriers had a higher anti-JCV antibody index than non-carriers (3.20 vs $1.34, p=0.008$ ) although anti-JCV antibodypositivity rates did not differ. Patients treated with fingolimod had a higher antibody index than other patients (1.46 vs $0.64, p=0.039)$ and treatment period had a positive correlation with antibody index $(p=0.018)$. Multivariate logistic regression analysis revealed that age was positively associated, and $H L A-D R B 1^{*} 15$ was negatively associated with anti-JCV antibody positivity (odds ratio $[\mathrm{OR}]=1.06, p=0.006$, and $\mathrm{OR}=0.37, p=0.028$, (Continued on next page)
\end{abstract}

\footnotetext{
* Correspondence: kira@neuro.med.kyushu-u.ac.jp

${ }^{+}$Mitsuru Watanabe and Yuri Nakamura contributed equally to this work.

${ }^{1}$ Department of Neurology, Neurological Institute, Graduate School of

Medical Sciences, Kyushu University, 3-1-1 Maidashi, Higashi-ku, Fukuoka

812-8582, Japan

${ }^{2}$ Department of Neurology, Brain and Nerve Center, Fukuoka Central

Hospital, International University of Health and Welfare, 2-6-11 Yakuin,

Chuo-ku, Fukuoka 810-0022, Japan

Full list of author information is available at the end of the article
}

(c) The Author(s). 2020 Open Access This article is licensed under a Creative Commons Attribution 4.0 International License, which permits use, sharing, adaptation, distribution and reproduction in any medium or format, as long as you give appropriate credit to the original author(s) and the source, provide a link to the Creative Commons licence, and indicate if changes were made. The images or other third party material in this article are included in the article's Creative Commons licence, unless indicated otherwise in a credit line to the material. If material is not included in the article's Creative Commons licence and your intended use is not permitted by statutory regulation or exceeds the permitted use, you will need to obtain permission directly from the copyright holder. To view a copy of this licence, visit http://creativecommons.org/licenses/by/4.0/ The Creative Commons Public Domain Dedication waiver (http://creativecommons.org/publicdomain/zero/1.0/) applies to the data made available in this article, unless otherwise stated in a credit line to the data. 
(Continued from previous page)

respectively). Excluding $H L A-D R B 1^{*} 15$-carriers, $D R B 1^{*} 04$ was an independent risk factor for the presence of anti-JCV antibody $(\mathrm{OR}=5.50, p=0.023)$.

Conclusions: HLA-DRB1*15 is associated with low anti-JCV antibody positive rate and low JCV antibody index, and in the absence of $D R B 1 * 15, D R B 1{ }^{*} 04$ carriers are associated with a high antibody positive rate in Japanese, suggesting the effects of two susceptible HLA-DRB1 alleles on anti-JCV antibody serostatus differ.

Keywords: Fingolimod, JC virus, Human leukocyte antigen (HLA), Multiple sclerosis, Progressive multifocal leukoencephalopathy

\section{Background}

Progressive multifocal leukoencephalopathy (PML) is a rare but frequently fatal demyelinating disease caused by JC virus (JCV) [1-3]. In PML, pathogenic variants of JCV invade the brain either within B cells or as cell-free virus, and infect oligodendrocytes, leading to the apoptosis of infected oligodendrocytes and multifocal demyelination, particularly under conditions of reduced immune surveillance in the central nervous system [1-4]. Some diseasemodifying drugs (DMDs) for multiple sclerosis (MS) can cause PML [5]. Following the long-term usage of natalizumab, MS patients with anti-JCV antibody, particularly those with a high antibody index, have a high risk of developing PML [6-8]. Although the incidence rate of fingolimodassociated PML was estimated to be low (0.056-0.069 per 1000 individuals) worldwide, especially in Europe and the USA [5, 9], 4 Japanese patients on fingolimod have developed PML to date, and the incidence rate of fingolimodassociated PML in Japan is estimated to be 10 times higher (0.58-0.65 per 1000) than other countries [10-12]. However, the reason for this remains to be elucidated.

A previous study reported that Scandinavian and German MS patients with anti-JCV antibodies had a significantly lower frequency of the human leukocyte antigen (HLA)-DRB1*15 haplotype than those without anti-JCV antibodies, suggesting the DRB1*15 haplotype is negatively associated with anti-JCV antibody positivity [13]. A recent Spanish study revealed that older age increased anti-JCV antibody positivity while $H L A-D R B 1 * 15$ : 01 carriers had marginally lower anti-JCV antibody positivity rates than $D R B 1 * 15: 01$ non-carriers $(p=0.056)$ [14]. These findings suggest that anti-JCV antibody serostatus are influenced by $H L A$ class II alleles.

Although the detailed mechanism of JCV clearance by a host remains to be elucidated, the immune control of JCV mostly depends on cellular immunity [2-4]. Although high titres of anti-JCV antibodies do not prevent the development of PML [4, 15-18], they can be used as a predictive marker for natalizumab-PML in MS patients [6-8]. It is postulated that host $\mathrm{CD}_{4}^{+} \mathrm{T}$ cells recognizing JCV antigens secrete proinflammatory cytokines that upregulate HLA class I molecules on JCV-infected cells, and that the presentation of viral antigens by HLA class
I molecules promotes $\mathrm{CD} 8^{+}$cytotoxic $\mathrm{T}$ cells to eliminate JCV-infected cells [19]. This $\mathrm{CD}^{+}{ }^{+} \mathrm{T}$ cell response varies according to $H L A$ class II alleles [20], resulting in distinct forms of JCV clearance. Because high levels of anti-JCV antibodies might reflect the high replicative activity of JCV under poor viral clearance whereas negative or low JCV antibody levels reflect strong viral clearance [13, 21-24], differences in $\mathrm{CD}^{+} \mathrm{T}$ cell responses by $H L A$ class II alleles might be related to anti-JCV antibody serostatus.

The genetic backgrounds of MS differ between Caucasians and Japanese. Although HLA-DRB1*15:01 is strongly associated with MS in Europeans and Japanese, $D R B 1 * 04: 05$, which is rare in Caucasians, is also a frequent and strong genetic risk factor in Japanese [25-29]. Therefore, we hypothesized that distinct disease-susceptible HLA class II alleles between Caucasian and Japanese patients with MS are associated with differences in JCV clearance and anti-JCV antibody serostatus, which may in part be related to the difference in risk for fingolimod-PML between Caucasian and Japanese patients. Because DNA from Japanese patients with fingolimod-PML was not available for $H L A$ genotyping, we studied the relationship between anti-JCV antibody serostatus and HLA class II alleles in Japanese MS patients with and without fingolimod to assess whether MS-susceptible HLA class II alleles influenced anti-JCV antibody serostatus. The results of the current study suggest why fingolimod-PML risk is higher in Japanese patients compared with Caucasian patients.

\section{Methods \\ Participants}

We enrolled 128 Japanese patients with MS in this study. Patients were recruited from the Department of Neurology at Kyushu University Hospital (Fukuoka, Japan), Kyoto Min-Iren-Chuo Hospital (Kyoto, Japan) and Kaikoukai Jyousai Hospital (Nagoya, Japan). A diagnosis of MS was based on the 2010 McDonald criteria [30]. Medical records and laboratory data of patients were retrospectively reviewed. Disease severity was evaluated using Kurtzke's Expanded Disability Status Scale (EDSS) [31]. Serum samples were collected between 1 
July 2014 and 31 December 2018 and stored at $-80{ }^{\circ} \mathrm{C}$ at each hospital.

\section{Standard protocol approval, registration, and patient consent}

This study was reviewed and approved by the Ethical Committee of Kyushu University (approved number 575-08). All patients provided written informed consent.

\section{Measurement of anti-JCV antibody}

Serum anti-JCV antibody serostatus and index were determined using a second-generation two-step assay [32] performed at Focus Diagnostics (Cypress, CA, USA).

\section{HLA class II genotyping}

Genotyping of the $H L A-D R B 1$ and $-D P B 1$ alleles of participants was performed by hybridization between polymerase chain reaction amplification products of the genes and sequence-specific oligonucleotide probes as described previously [33].

\section{Statistics}

Categorical variables were described by counts and percentages, and continuous and ordinal variables by median and interquartile ranges (IQRs) (and range, if necessary). Demographic features were compared between anti-JCV antibody-positive and antibodynegative groups using Fisher's exact test or the Wilcoxon test. Anti-JCV antibody frequency and index were also compared between two groups using Fisher's exact test and the Wilcoxon test, respectively. In addition to the comparison of anti-JCV antibody frequency and index between patients with and without each $H L A$ allele (shown as four-digits), we also compared them between HLA allele groups (shown as two-digits), which reflect HLA serotypes, on the basis of their similar function in each allele group. The associations between anti-JCV antibody index and age, months of treatment with fingolimod, and number of lymphocytes were tested using linear regression models. The linear dose effect of each HLA allele on anti-JCV antibody seropositivity was evaluated with the Cochran-Armitage trend test. A multivariable logistic regression model was used to identify independent factors that predicted the positivity of anti-JCV antibody. All analyses were performed using JMP ${ }^{\circ}$ Pro version 14.1.0 software (SAS Institute, Cary, NC, USA). The significance level was set at $p<0.05$.

\section{Results}

\section{Demographics and anti-JCV antibody status of} participants

The demographics and anti-JCV antibody status of participants are shown in Table 1 . Of 128 patients with
Table 1 Demographic features and anti-JCV antibody status of study participants

\begin{tabular}{ll}
\hline & $\begin{array}{l}\text { MS patients } \\
(n=128)\end{array}$ \\
\hline Sex, female & $93(72.7 \%)$ \\
Age, years & 39 [IQR 32-48; range 20-70] \\
Disease duration, years & 10 [IQR 5-16; range 0-43] \\
EDSS score & 2.0 [IQR 1.0-3.5; range 0-8.0] \\
Lymphocyte counts at & 709 [IQR 447-1539; range 222-3491] \\
sampling, / $\mu \mathrm{L}$ & 83 (64.8\%) \\
History of fingolimod usage & 64 (50.0\%) \\
Use of fingolimod at sampling & 86 (67.2\%) \\
Anti-JCV antibody, positive & 1.19 [IQR 0.21-3.09; range 0.06-4.04] \\
Anti-JCV antibody index &
\end{tabular}

Values indicate the median [IQR and range] or count (\%)

EDSS Expanded Disability Status Scale, IQR interquartile range, JCV JC virus, MS multiple sclerosis

${ }^{a}$ Other disease-modifying drugs were used in 39 patients $(30.5 \%)$ at sampling: interferon- $\beta-1 \mathrm{a}$ in 15 (11.7\%), dimethyl fumarate in $13(10.2 \%)$, glatiramer acetate in $4(3.1 \%)$, natalizumab in $3(2.3 \%)$, interferon- $\beta-1 b$ in $2(1.6 \%)$, azathioprine in $1(0.8 \%)$, and methotrexate in $1(0.8 \%)$

MS, 83 (64.8\%) had a history of fingolimod usage and 64 $(50.0 \%)$ were under treatment with fingolimod at sampling. Eighty-six participants (67.2\%) were positive for anti-JCV antibody and the median anti-JCV antibody index was $1.19(\mathrm{IQR}=0.21-3.09)$.

\section{HLA class II alleles in participants}

Phenotype frequencies of the $H L A$ class II of participants are shown in Additional file 1: Table S1. By four-digit alleles, 51 participants (39.8\%) carried $H L A-D R B 1 \% 04: 05$ and $42(32.8 \%)$ had $D R B 1 * 15: 01$. By two-digit alleles, 81 (63.3\%) had HLA-DRB1*04 and 65 (50.8\%) had $D R B 1 * 15$. The phenotype frequencies were not significantly different between MS patients with and without fingolimod treatment (Additional file 1: Table S1).

\section{Age is positively associated with anti-JCV antibody positivity and index}

Next, we assessed the association between anti-JCV antibody serostatus and patients' demographic and clinical features. Anti-JCV antibody-positive patients were older than antibody-negative patients $(p=0.001$; Table 2$)$ and age was positively, but weakly, associated with anti-JCV antibody index $(r=0.214, p=0.015$; Fig. 1a). Although lymphocyte counts were similar between anti-JCV antibodypositive and antibody-negative groups, they tended to have a weak negative association with the anti-JCV antibody index $(r=-0.169, p=0.057)$. Sex, disease duration, and EDSS scores did not differ by anti-JCV antibody serostatus and were not associated with the anti-JCV antibody index. 
Table 2 Comparison of the demographic features and anti-JCV antibody status between anti-JCV antibody-positive and -negative patients with MS

\begin{tabular}{llll}
\hline & Positive $(n=86)$ & Negative $(n=42)$ & $p$ value \\
\hline Sex, female & $60(69.8 \%)$ & $33(78.6 \%)$ & 0.399 \\
Age, years & $43.5[33.0-50.3]$ & $35.0[27.8-40.3]$ & 0.001 \\
Disease duration, years & $11[5-18]$ & $9[5-15]$ & 0.455 \\
EDSS score & $2.0[1.0-4.1]$ & $2.0[1.0-3.5]$ & 0.576 \\
Lymphocyte counts at sampling, / $\mu \mathrm{L}$ & $645[427-1402]$ & $1158[521-1589]$ & 0.139 \\
Anti-JCV antibody index & $2.47[1.15-3.29]$ & $0.16[0.11-0.21]$ & $<0.001$ \\
\hline
\end{tabular}

Values indicate the median [IQR] or count (\%)

EDSS Expanded Disability Status Scale, IQR interquartile range, JCV JC virus

\section{Duration of fingolimod treatment is positively associated with anti-JCV antibody index}

When comparing anti-JCV antibody serostatus between patients with and without a history of fingolimod treatment ( $n=83$ and 45 , respectively), no significant differences were observed for the positivity rate or anti-JCV antibody index. However, patients with fingolimod treatment at sampling $(n=64)$ had a higher antibody index than those without $(n=64)(1.46[0.34-3.26]$ vs 0.64 [0.16-2.61], $p=0.039$; Table 3). Duration of treatment with fingolimod was positively associated with the antiJCV antibody index in patients treated with fingolimod at sampling ( $r=0.296, p=0.018$; Fig. $1 b)$, but not in patients with a history of fingolimod treatment $(r=0.204$, $p=0.066$ ). The positive correlation between duration of treatment with fingolimod and anti-JCV antibody index was still significant in patients under fingolimod treatment at sampling after correcting for age $(p=0.022)$.

\section{Relationship between anti-JCV serostatus and HLA class II alleles}

When we analyzed HLA class II by four-digit alleles, $H L A-D R B 1 * 15: 01$ carriers $(n=42)$ had a lower anti-JCV antibody-positive rate than $D R B 1 * 15: 01$ non-carriers
( $50 \%$ vs $76 \%, p=0.005$; Fig. $2 \mathrm{a}$ ). However, the positive rate of anti-JCV antibody was not different between HLA-DRB1*04:05 carriers $(n=51)$ and non-carriers $(71 \%$ vs $65 \%, p=0.567)$. When analyzing $H L A$ class II by twodigit alleles, $H L A-D R B 1 * 15$ carriers $(n=65)$ had a lower positivity rate of anti-JCV antibody compared with $D R B 1 * 15$ non-carriers (57\% vs $78 \%, p=0.015$; Fig. $2 a)$. Again, anti-JCV antibody positive rates were similar between $H L A-D R B 1^{*} 04$ carriers $(n=81)$ and non-carriers (70\% vs $62 \%, p=0.335)$. However, when we excluded HLA-DRB1*15 carriers because DRB1*15 had a very strong effect on anti-JCV antibody status, DRB1:04 carriers $(n=50)$ had a higher anti-JCV antibody positive rate compared with DRB1*04 non-carriers $(n=13)(84 \%$ vs $54 \%, p=0.030$; Fig. $2 \mathrm{a}$ ). Anti-JCV antibody positivity rates were estimated to decrease per $H L A-D R B 1 * 15$ allele $(p=0.008)$ and to increase per DRB1*04 allele when excluding DRB1*15 $(p=0.022)$, which suggests a genedosage effect (Fig. 2b). In addition, in the fingolimodtreated group, $H L A-D R B 1 * 15: 01$ carriers $(n=22)$ had a significantly lower positivity rate of anti-JCV antibody compared with $D R B 1 * 15: 01$ non-carriers $(50 \%$ vs $86 \%$, $p=0.006$; Additional file 2: Figure S1a). Analyzing $H L A$ class II by two-digits, $H L A-D R B 1 * 15$ carriers $(n=32)$
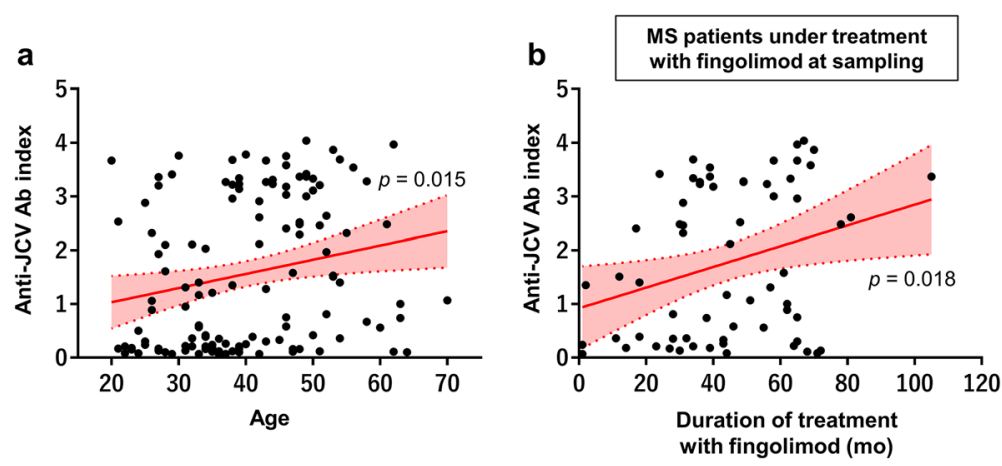

Fig. 1 Correlation of anti-JCV antibody index and clinical parameters in patients with MS. a Correlation between anti-JCV antibody index and age in all participants $(n=128)$. b Correlation between anti-JCV antibody index and duration of treatment with fingolimod in MS patients under fingolimod treatment at sampling $(n=64)$. The lines represent the linear regression of the data. Translucent bands indicate $95 \%$ confidence intervals. $p$ values were obtained using linear regression analyses. $\mathrm{Ab}=$ antibody; JCV $=\mathrm{JC}$ virus; $\mathrm{mo}=$ months; $\mathrm{MS}=$ multiple sclerosis 
Table 3 Comparison of the anti-JCV antibody status between MS patients with and without fingolimod treatment

\begin{tabular}{clll}
\hline History of fingolimod treatment & Yes $(n=83)$ & No $(n=45)$ & $p$ value \\
Anti-JCV antibody, positive & $59(71.1 \%)$ & $27(60.0 \%)$ & 0.239 \\
Anti-JCV antibody index & $1.40[0.26-3.18]$ & $0.57[0.16-2.97]$ & 0.129 \\
Fingolimod treatment at sampling & Yes $(n=64)$ & No $(n=64)$ & $p$ value \\
Anti-JCV antibody, positive & $47(73.4 \%)$ & $39(60.9 \%)$ & 0.187 \\
Anti-JCV antibody index & $1.46[0.34-3.26]$ & $0.64[0.16-2.61]$ & 0.039 \\
\hline
\end{tabular}

Values indicate the median [IQR] or count (\%)

$I Q R$ interquartile range, JCV JC virus, MS multiple sclerosis

tended to have a lower positivity rate of anti-JCV antibody compared with $D R B 1 * 15$ non-carriers $(63 \%$ vs $84 \%, p=0.088)$. When $H L A-D R B 1 * 15$ carriers were excluded, DRB1*04 carriers $(n=24)$ tended to have a higher anti-JCV antibody positive rate compared with $D R B 1 * 04$ non-carriers $(n=8)(92 \%$ vs $63 \%, p=0.085$; Additional file 2: Figure S1a). Such associations between $H L A$ alleles and anti-JCV antibody positivity rates were not seen in MS patients without fingolimod treatment (Additional file 2: Figure S1b).

The anti-JCV antibody index tended to be lower in HLA-DRB1*15:01 carriers compared with DRB1*15:01 non-carriers (median 0.35 vs $1.56, p=0.083$ ) and was lower in $D R B 1 * 15$ carriers than in non-carriers $(0.42$ vs 1.97, $p=0.037$, Fig. 2c). Moreover, in HLA-DRB1*15 non-carriers, $D R B 1^{*} 04$ carriers tended to have a higher anti-JCV index compared with DRB1*04 non-carriers (2.12 vs $0.36, p=0.062$, Fig. 2c).

In addition to HLA-DRB1*04:05 and DRB1*15:01, DRB1*04:10 carriers $(n=8)$ had a higher anti-JCV antibody index compared with non-carriers (3.29 vs 1.03 , $p=0.021$ ). Of $H L A-D R B 1 * 15: 01$ non-carriers, $D P B 1 * 04$ : 02 carriers $(n=13)$ had a higher anti-JCV antibody index compared with non-carriers $(n=64)$ (3.20 vs $1.34, p=$ 0.008). However, anti-JCV antibody-positive rates did not differ between these allele carriers and non-carriers. No other $H L A$ class II alleles were associated with antiJCV antibody serostatus.

\section{Age and HLA-DRB1*15 are independently associated with anti-JCV antibody serostatus by multivariate analyses}

To identify independent factors that predict anti-JCV antibody seropositivity, we performed multivariate logistic regression analysis. It showed that age was positively, and $H L A-D R B 1 * 15$ was negatively, associated with antiJCV antibody seropositivity (odds ratio $[\mathrm{OR}]=1.06, p=$ 0.006 and $\mathrm{OR}=0.37, p=0.028$, respectively; Table 4$)$. In $H L A-D R B 1 * 15$ non-carriers $(n=63), D R B 1 * 04$ was an independent risk factor for possessing anti-JCV antibodies by multivariate logistic regression analysis $(\mathrm{OR}=5.50$, $p=0.023$; Table 5 ). In both analyses, fingolimod treatment itself was not an independent factor for anti-JCV antibody seropositivity. Moreover, we conducted another multivariate analysis in patients under fingolimod treatment $(n=64)$. Again, age and $H L A-D R B 1 * 15$ were independent risk factors for anti-JCV antibody seropositivity $(\mathrm{OR}=1.42, p=0.002$, and $\mathrm{OR}=0.02, p=0.022$, respectively; Additional file 1: Table S2); however, treatment duration or lymphocyte count were not independent risk factors ( $p=0.880$ and 0.094 , respectively; Additional file 1 : Table S2).

\section{Discussion}

The current study of Japanese patients with MS disclosed that $H L A-D R B 1 * 15$ was associated with low antiJCV antibody positivity and low antibody index, and that in the absence of $D R B 1 * 15, D R B 1 * 04$ carriers were associated with high antibody seropositivity. Moreover, HLA$D R B 1 * 15$ allele and DRB1*04 allele without DRB1*15 demonstrated a gene-dosage effect on JCV antibody positivity. Additionally, ageing was positively associated with JCV antibody positivity and index while long-term fingolimod usage increased the JCV antibody index even after adjusting for age.

In addition to the strong negative association of $H L A$ $D R B 1 * 15$ with JCV antibody positivity and index, we clearly showed the HLA-DRB1*15 allele had negative gene-dose effects and the $D R B 1^{*} 04$ allele had positive gene-dose effects on anti-JCV antibody positivity. These findings indicate the influence of these gene alleles on anti-JCV antibody serostatus. This study is the first to report a lower JCV antibody index in $H L A-D R B 1 * 15$ positive MS patients compared with $D R B 1 * 15$-negative patients, which suggests that anti-JCV antibody production is decreased in $D R B 1 * 15$ carriers. The higher frequency of JCV antibody positivity in $H L A-D R B 1^{*} 04$ carriers was observed only after excluding $D R B 1 * 15$ carriers, which suggests the dominance of $H L A-D R B 1 * 15$ over DRB1*04 for anti-JCV antibody serostatus.

The findings of this study suggest that the immune control of JCV might be partly related to the strong negative association of $H L A-D R B 1 * 15$ with JCV antibody positivity and index. However, the detailed mechanism of JCV elimination by the host remains to be elucidated. Although JCV-specific antibody titres are elevated in PML patients $[15-17,19]$, intrathecal or serum anti-JCV 

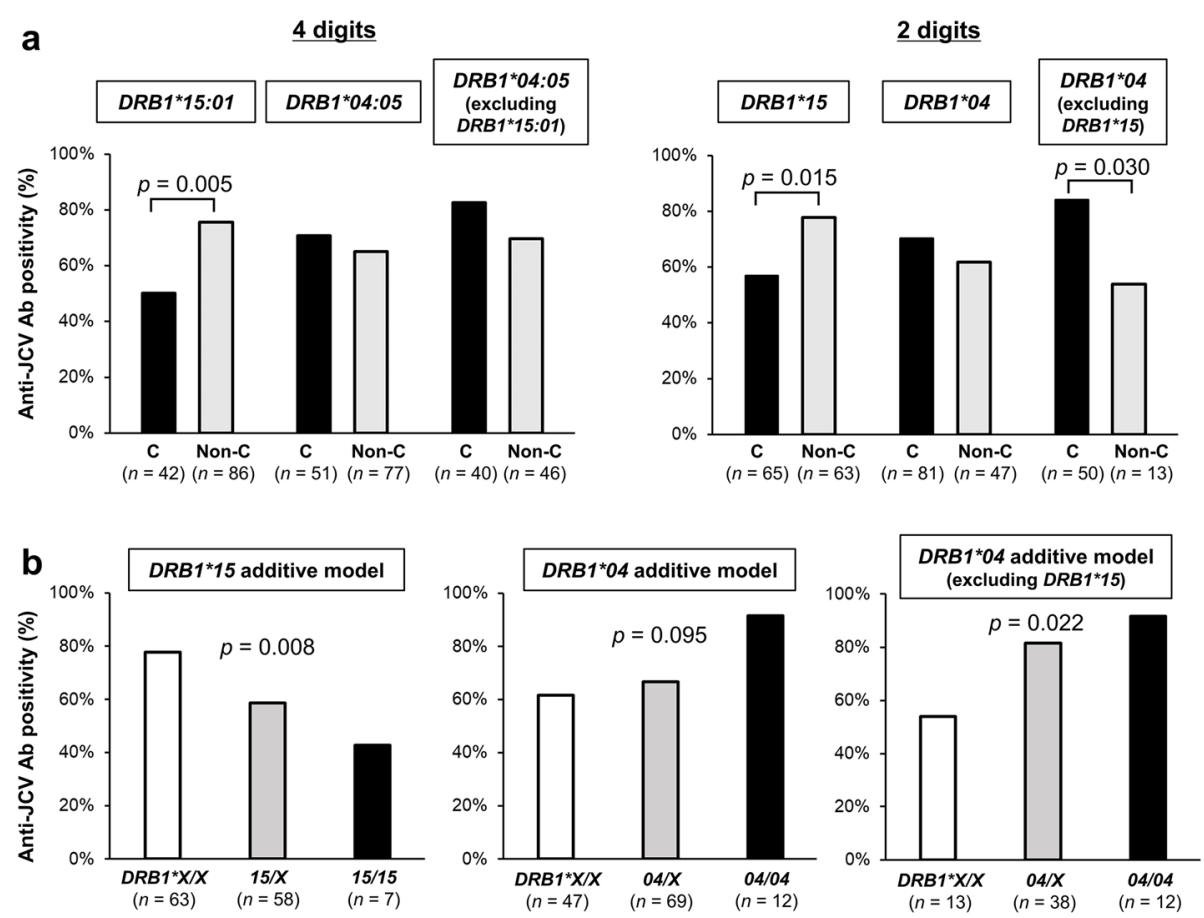

C
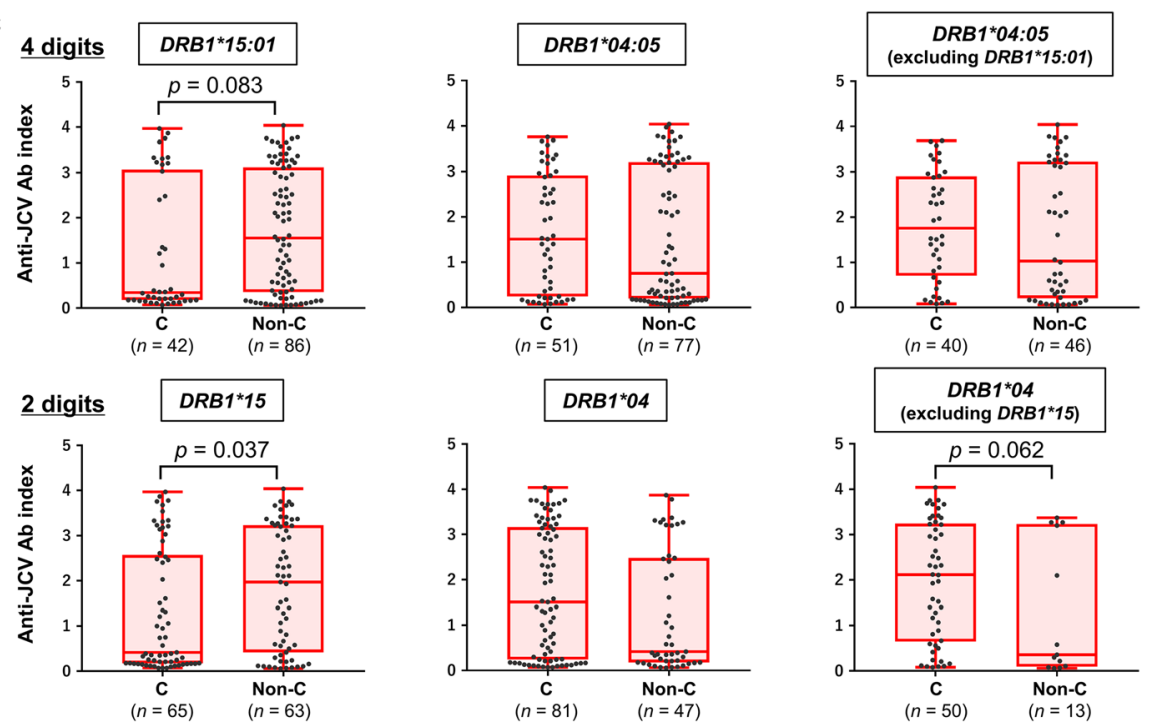

Fig. 2 Relationship between anti-JCV antibody serostatus and HLA class II alleles in Japanese MS patients. a Anti-JCV antibody-positive rates were compared between carriers and non-carriers of each HLA-DRB1 allele. The HLA-DRB1 allele was analyzed and is shown as 4 digits in the left panel and as 2 digits in the right panel. $p$ values were obtained using Fisher's exact test. $\mathbf{b}$ The relationships between anti-JCV antibody seropositivity rates and number of $H L A-D R B 1^{*} 15$ or DRB $1^{*} 04$ alleles are shown. $X$ in the figure indicates other alleles specified in each panel (other than $D R B 1^{*} 15$ in the left panel and other than $D R B 1^{*} 04$ in the middle and right panels). $p$ values were obtained using the Cochran-Armitage trend test. c Anti-JCV antibody indices were compared between carriers and non-carriers of each HLA-DRB1 allele. HLA-DRB1 alleles were analyzed and are shown as 4 digits in the upper panels and as 2 digits in the lower panels. Boxes depict the median and interquartile ranges, and upper/lower whiskers extend from the hinge toward the largest/smallest values. $p$ values were obtained using the Wilcoxon test. $A b=a n t i b o d y ; C=c a r r i e r s ;$ $H L A=$ human leukocyte antigen; JCV = JC virus; MS = multiple sclerosis; non-C = non-carriers

antibodies do not prevent the development of PML. Most individuals who persistently shed JCV in their urine are seropositive [6], some seropositive individuals are viremic [17], and some individuals with PML have high copy numbers of viral DNA despite very high concentrations of anti-JCV antibodies in their cerebrospinal fluid (CSF) $[17,19]$. Furthermore, a high JCV antibody index (>0.9) was strongly associated with PML in 
Table 4 Multivariate logistic regression analysis of factors contributing to anti-JCV antibody positivity in patients with MS

\begin{tabular}{lll}
\hline All participants $(n=128)$ & OR $(95 \% \mathrm{Cl})$ & $p$ value \\
\hline Age & $1.06(1.02-1.10)$ & 0.006 \\
HLA-DRB ${ }^{*} 15$ & $0.37(0.16-0.90)$ & 0.028 \\
Sex (male) & $1.59(0.63-4.00)$ & 0.321 \\
Fingolimod usage at sampling & $1.76(0.52-5.89)$ & 0.361 \\
Lymphocyte count $(\times 1000 / \mu \mathrm{L})$ & $1.14(0.47-2.79)$ & 0.771 \\
HLA-DRB1*04 & $0.92(0.39-2.19)$ & 0.850
\end{tabular}

CI confidence interval, HLA human leukocyte antigen, JCV JC virus, MS multiple sclerosis, $O R$ odds ratio

natalizumab-treated MS patients [6-8]. These observations collectively indicate that high levels of anti-JCV antibodies are not related to JCV clearance, but rather reflect the high amount of JCV and predict the risk of developing PML. Therefore, immune control of JCV is mainly dependent on cell-mediated immunity [2-4]. It was hypothesized that upon recognition of the viral capsid protein, VP-1, CD $4^{+} \mathrm{T}$ cells produce interferon- $\gamma$, which upregulates HLA class I molecules on JCVinfected cells. Presentation of the viral large T cell antigen by HLA class I molecules activates $\mathrm{CD}^{+} \mathrm{T}$ cells, which remove JCV-infected cells via granzyme $\mathrm{B}$ and other cytotoxic molecules [19]. The findings that PML tends to develop in idiopathic $\mathrm{CD} 4^{+} \mathrm{T}$ lymphocytopenia [34], that HIV-seropositive patients with PML lack CD4 ${ }^{+}$ $\mathrm{T}$ cell responses to JCV [35], and PML patients with low numbers of CSF $\mathrm{CD}^{+}{ }^{+} \mathrm{T}$ cells remain persistently JCVpositive in the CSF [36] collectively suggest the crucial role of $\mathrm{CD}^{+} \mathrm{T}$ cells as well as $\mathrm{CD}^{+}$cytotoxic $\mathrm{T}$ cells in the elimination of JCV and prevention of PML. Indeed, increased numbers of JCV-specific $\mathrm{CD}^{+} \mathrm{T}$ cells were found in the peripheral blood of PML survivors [15, 35]. This $\mathrm{CD}^{+} \mathrm{T}$ cell response varies according to HLA class II molecules that present the viral antigens [20]. Therefore, differences in $\mathrm{CD}^{+} \mathrm{T}$ cell responses related to distinct $H L A$ class II alleles are thought to influence the efficacy of JCV clearance [13, 20].

Table 5 Multivariate logistic regression analysis of factors contributing to anti-JCV antibody positivity in patients with MS excluding carriers of HLA-DRB1*15

\begin{tabular}{lll}
\hline Patients without HLA-DRB1*15 $(n=63)$ & OR $(95 \% \mathrm{Cl})$ & $p$ value \\
\hline HLA-DRB1*04 & $5.50(1.26-23.94)$ & 0.023 \\
Age & $1.04(0.98-1.11)$ & 0.149 \\
Fingolimod usage at sampling & $2.40(0.33-17.32)$ & 0.384 \\
Sex (male) & $1.78(0.38-8.46)$ & 0.467 \\
Lymphocyte count $(\times 1000 / \mu \mathrm{L})$ & $0.85(0.20-3.66)$ & 0.832 \\
\hline
\end{tabular}

CI confidence interval, HLA human leukocyte antigen, JCV JC virus, MS multiple sclerosis, $O R$ odds ratio
The negative association between $H L A-D R B 1 * 15$ and anti-JCV antibodies suggests $H L A-D R B 1 * 15$ carriers present JCV antigens to $\mathrm{CD} 4^{+} \mathrm{T}$ cells to activate $\mathrm{CD} 8^{+}$ cytotoxic $\mathrm{T}$ cell responses that eliminate JCV. Eradication of JCV may result in negative or low anti-JCV antibody serostatus in $H L A-D R B 1 * 15$ carriers. By contrast, $H L A-D R B 1^{*} 04$ carriers were reported to have very low $\mathrm{T}$ cell responses to JCV compared with HLA-DRB1*15 carriers [20]. Therefore, reduced $\mathrm{T}$ cell responses against JCV might be related to inefficient viral antigen presentation by $H L A-D R B 1 * 04$ molecules that results in poor viral elimination and enhanced viral replication, which stimulates B cells to produce high levels of anti-JCV antibodies [13, 20, 22, 24]. The low JCV antibody levels in HLA-DRB1*15 carriers and high JCV antibody levels in $H L A-D R B 1 * 04$ carriers excluding HLA-DRB1*15 carriers found in this study might be explained by this theory.

Although $H L A-D R B 1 * 15$ is a common susceptibility gene for MS in Caucasians and Japanese, the phenotype frequency of $D R B 1 * 15: 01$ ranges between $45 \%$ and $60 \%$ in European MS patients (10-30\% in the general population) but is only approximately $30 \%$ in Japanese patients (16-17\% in the general population) [26, 27, 29, 37-39]. Conversely, the phenotype frequency of $H L A-D R B 1 * 04$ : 05 was reported to be $0.7 \%$ in MS patients in Italy [37], and $0-5.3 \%$ in the European general population [40], but up to $25 \%$ in the Japanese general population and around $45 \%$ in Japanese MS patients [27, 29]. Anti-JCV antibody seropositivity rates in MS are higher in Japanese (approximately 70\% in our and previous studies) than in those of European descent $(50 \%-60 \%$ in Europe and the USA) [41-43]. This difference might be partly explained by the difference in proportions of JCV-resistant $D R B 1 * 15: 01$ and JCV-susceptible DRB1*04:05 alleles between these two races. Thus, the high frequency of fingolimod-PML in Japanese may in part be related to these common susceptibility $H L A$ genes. This possibility should be verified in future large-scale studies.

In fingolimod users, ageing is a risk and $D R B 1 * 15: 01$ is a strong resistance factor for anti-JCV antibody positivity. Ageing is a risk for anti-JCV antibody positivity in Europeans and Japanese [41-44]. The increase of JCV antibody index levels with the long-term usage of fingolimod, which was significant even after correcting for age, is consistent with a previous study in Japanese [42]. Fingolimod acts as a functional antagonist of the sphingosine 1-phosphate receptor, which results in the inhibition of central memory $\mathrm{T}$ cell egress from lymph nodes [45]. This effect is thought to be its beneficial mode of action in MS [45]. Although the precise mechanism of fingolimod-PML is still poorly defined, $\mathrm{T}$ cell surveillance in the central nervous system may be dampened upon fingolimod usage. The finding that 
lower lymphocyte counts tended to be associated with a higher anti-JCV antibody index in our MS patients may support this mechanism. It was established that a high JCV antibody index (>0.9) was a risk for developing PML in natalizumab-treated MS patients [8]. Although it remains to be established whether a high JCV antibody index is also a risk factor for fingolimod-PML, our study results suggest that MS patients with these risk factors, namely, aged, non-DRB1*15:01 carriers with anti-JCV antibody, should be frequently monitored for JCV antibody index and PML lesions by MRI upon long-term usage of fingolimod. Additionally, DMDs that lack PML risk, such as first line injectables, may be recommended for DRB1*04 carriers with MS because DRB1*04:05-positive MS patients, especially Japanese patients, have a relatively mild disease course [27, 29].

There were several limitations in our study. First, a high anti-JCV antibody index is not a proven risk factor for developing PML associated with fingolimod treatment. Thus, although our study showed the differential effects of two HLA class II susceptible alleles for MS related to anti-JCV antibody serostatus, it does not necessarily mean that these alleles are susceptibility or resistance genes for PML development itself in MS patients treated with fingolimod. Because only four patients with fingolimod-PML have been reported in Japan, none of whom were at our institute $[11,12]$, we could not determine the HLA alleles in fingolimod-PML patients. Second, we did not examine JCV DNA in blood, primarily because its presence in blood is not a reliable predictor of PML. JCV DNA is often not detected in the blood of PML patients whereas it is occasionally detected in the blood of HIV-positive patients without PML [46]. Furthermore, natalizumab-treated patients with detectable JCV DNA in the blood $(<1 \%)$ did not develop PML with continued natalizumab treatment, and JCV DNA was not detectable in blood collected prior to PML development in natalizumab-treated PML patients [47]. Therefore, investigating the association between anti-JCV antibody serostatus and HLA alleles might help us to understand the immune responses against JCV and resultant risk of PML in MS patients. Third, we did not examine T cell response to JCV peptides. Because stock sera are much easier to collect than live $\mathrm{T}$ cells, we investigated the correlation between antiJCV antibodies and HLA alleles. Because our data suggest that differences in the immunogenetic background among races are at least partly related to anti-JCV antibody serostatus, T cell responses to JCV peptides should be examined as the next step to elucidate differences in the defense mechanism against JCV by HLA alleles in MS patients. Fourth, we showed data for HLA as fourand two-digits in this study. This was based on the hypothesis that all alleles in each allele group have a similar function. However, some alleles in the same allele group can present different antigen peptides and will therefore have different $\mathrm{T}$ cell activation capabilities [20]. Future large-scale studies are needed to identify whether the effects on anti-JCV serostatus are similar among four-digit HLA alleles belonging to identical twodigit allele groups. Fifth, we did not genotype other $H L A$ alleles such as $H L A-D Q B 1$. Because previous studies showed that the $H L A-D Q B 1 * 06: 03$ haplotype was also positively associated with JCV-serostatus [13] and that phenylalanine at position 9 of $H L A-D Q B 1$ was associated with MS susceptibility in Japanese [48], susceptible $H L A$ alleles other than HLA-DRB1 and -DPB1 may also be related to the immune response against JCV in patients with MS. Therefore, future studies should assess the association between other HLA alleles and JCV serostatus. Finally, our study was a cross-sectional study enrolling a relatively small number of MS patients because of the rarity of MS in Japanese. The low median EDSS scores in this study cohort might reflect the milder disability of Japanese patients with MS compared with European patients with a similar disease duration and age $[49,50]$. Therefore, we think that the relatively low EDSS scores in our patients are not necessarily related to selection bias. However, our findings should be regarded as preliminary and confirmed by large-scale longitudinal studies.

\section{Conclusions}

HLA-DRB1*15:01 and DRB1*15 alleles are associated with low JCV antibody positive rate and index, whereas $D R B 1 * 04$ is associated with high JCV antibody positive rate in Japanese MS patients, excluding $D R B 1 * 15$ carriers. Therefore, the two MS-susceptible $H L A-D R B 1$ alleles exert distinct effects on anti-JCV antibody serostatus in Japanese patients with MS.

\section{Supplementary information}

Supplementary information accompanies this paper at https://doi.org/10. 1186/s12974-020-01865-7.

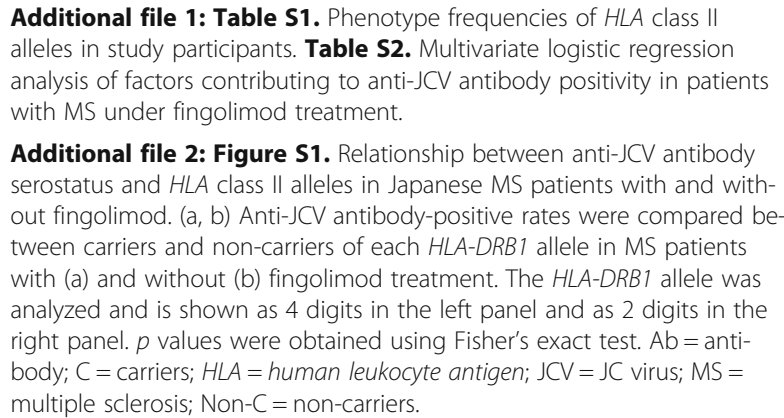

Additional file 1: Table S1. Phenotype frequencies of HLA class II alleles in study participants. Table S2. Multivariate logistic regression analysis of factors contributing to anti-JCV antibody positivity in patients with MS under fingolimod treatment.

Additional file 2: Figure S1. Relationship between anti-JCV antibody serostatus and HLA class II alleles in Japanese MS patients with and without fingolimod. $(a, b)$ Anti-JCV antibody-positive rates were compared between carriers and non-carriers of each HLA-DRB1 allele in MS patients with (a) and without (b) fingolimod treatment. The HLA-DRB1 allele was analyzed and is shown as 4 digits in the left panel and as 2 digits in the right panel. $p$ values were obtained using Fisher's exact test. $A b=$ antibody; $C=$ carriers; HLA = human leukocyte antigen; JCV = JC virus; $M S=$ multiple sclerosis; Non- $\mathrm{C}=$ non-carriers.

\section{Abbreviations}

CSF: Cerebrospinal fluid: DMD: Disease-modifying drug; EDSS: Expanded Disability Status Scale; HLA: Human leukocyte antigen; IQR: Interquartile 
range; JCV: JC virus; MS: Multiple sclerosis; OR: Odds ratio; PML: Progressive multifocal leukoencephalopathy

\section{Acknowledgements}

We thank Biogen Idec for measuring the anti-JCV antibody serostatus. We thank J. Ludovic Croxford from Edanz Group (www.edanzediting.com) for English proofreading and editing of this manuscript.

\section{Authors' contributions}

YN and JK conceived and designed the study. MW, YN, NI, MT, AS, FH, and TM collected data. MW and YN analyzed the data. All authors interpreted the data. MW, YN, and JK wrote and revised the manuscript. All authors read and approved the final manuscript.

\section{Funding}

This study was supported in part by grants from the Japan Society for the Promotion of Science (JSPS) KAKENHI (grant nos. 16H02657, 16 K09694, 18H06214, 18 K07529, 19H01045, 19 K07995, 19 K07997, and 19 K21317), and a Health and Labour Sciences Research Grant on Intractable Diseases [H29Nanchitou (Nan)-Ippan-043] from the Ministry of Health, Labour and Welfare, Japan.

\section{Availability of data and materials}

The datasets generated and/or analyzed during the present study will be available from the corresponding author based on the guidelines of the Ethics Committee of Kyushu University upon reasonable request from any qualified investigator.

\section{Ethics approval and consent to participate}

The study received ethical approval from the Ethics Committee of Kyushu University (approval number 575-08) and written informed consent was obtained from all participants.

\section{Consent for publication}

Not applicable.

\section{Competing interests}

MW received speaker honoraria and consultant fees from Novartis Pharma and received a research grant from JSPS KAKENHI (grant no. 19 K07995). YN received a grant and salary from Mitsubishi Tanabe Pharma, Bayer Yakuhin, Ltd. and Japan Blood Products Organization, received speaker honoraria from Novartis Pharma, and received a grant from JSPS KAKENHI (grant nos. 18H06214 and 19 K21317). NI received grant support from Mitsubishi Tanabe Pharma, Osoegawa Neurology Clinic, Bayer Yakuhin, Ltd. and Japan Blood Products Organization, and received a research grant from JSPS KAKENHI (grant no. 18 K07529). AS received grant support from Yazuya. YK received a grant from JSPS KAKENHI (grant no. 19 K07997). RY received honoraria from Biogen Japan and received a research grant from JSPS KAKENHI (grant no. 16 K09694). TM received speaker honoraria payments from Mitsubishi Tanabe Pharma, Takeda Pharmaceutical Company, and Biogen Japan. JK received consultant fees, speaking fees and/or honoraria from Novartis Pharma, Mitsubishi Tanabe Pharma, Boehringer Ingelheim, Teijin Pharma, Takeda Pharmaceutical Company, Otsuka Pharmaceutical, Astellas Pharma, Pfizer Japan, Sumitomo Dainippon Pharma, and Eisai, and is supported by grants from JSPS KAKENHI (grant nos. 16H02657 and 19H01045) and Health and Labour Sciences Research Grants on Intractable Diseases (H29-Nanchitou (Nan)-Ippan-043). MT and FH declare that they have no competing interests.

\section{Author details}

'Department of Neurology, Neurological Institute, Graduate School of Medical Sciences, Kyushu University, 3-1-1 Maidashi, Higashi-ku, Fukuoka 812-8582, Japan. Department of Neurology, Brain and Nerve Center, Fukuoka Central Hospital, International University of Health and Welfare, 2-6-11 Yakuin, Chuo-ku, Fukuoka 810-0022, Japan. ${ }^{3}$ School of Pharmacy at Fukuoka, International University of Health and Welfare, 137-1 Enokizu, Okawa 831-8501, Japan. ${ }^{4}$ Department of Neurological Therapeutics, Neurological Institute, Graduate School of Medical Sciences, Kyushu University, 3-1-1 Maidashi, Higashi-ku, Fukuoka 812-8582, Japan. ${ }^{5}$ Kyoto MS Center, Kyoto Min-Iren-Chuo Hospital, 2-1 Uzumasatsuchimoto-cho, Ukyo-ku, Kyoto 616-8147, Japan. ${ }^{6}$ Department of Neurology, Kaikoukai Jyousai Hospital, 1-4 Kitabatake, Nakamura-ku, Nagoya 453-0815, Japan. ${ }^{7}$ Department of Neurology, National Hospital Organization Omuta National Hospital, 1044-1 Oaza, Tachibana, Omuta 837-0911, Japan. ${ }^{8}$ Translational Neuroscience Center, Graduate School of Medicine, and School of Pharmacy at Fukuoka, International University of Health and Welfare, 137-1 Enokizu, Okawa 831-8501, Japan.

Received: 29 February 2020 Accepted: 4 June 2020

Published online: 09 July 2020

\section{References}

1. Major EO. Progressive multifocal leukoencephalopathy in patients on immunomodulatory therapies. Annu Rev Med. 2010;61:35-47.

2. Tan CS, Koralnik IJ. Progressive multifocal leukoencephalopathy and other disorders caused by JC virus: clinical features and pathogenesis. Lancet Neurol. 2010;9:425-37.

3. Major EO, Yousry TA, Clifford DB. Pathogenesis of progressive multifocal leukoencephalopathy and risks associated with treatments for multiple sclerosis: a decade of lessons learned. Lancet Neurol. 2018;17:467-80.

4. Bellizzi A, Anzivino E, Rodio DM, Palamara AT, Nencioni L, Pietropaolo V. New insights on human polyomavirus JC and pathogenesis of progressive multifocal leukoencephalopathy. Clin Dev Immunol. 2013;2013:839719.

5. Berger JR. Classifying PML risk with disease modifying therapies. Mult Scler Relat Disord. 2017;12:59-63.

6. Gorelik L, Lerner $M$, Bixler $S$, Crossman $M$, Schlain B, Simon $K$, et al. Anti-JC virus antibodies: implications for PML risk stratification. Ann Neurol. 2010:68:295-303.

7. Bloomgren G, Richman S, Hotermans C, Subramanyam M, Goelz S, Natarajan A, et al. Risk of natalizumab-associated progressive multifocal leukoencephalopathy. N Engl J Med. 2012;366:1870-80.

8. Ho PR, Koendgen H, Campbell N, Haddock B, Richman S, Chang I. Risk of natalizumab-associated progressive multifocal leukoencephalopathy in patients with multiple sclerosis: a retrospective analysis of data from four clinical studies. Lancet Neurol. 2017;16:925-33.

9. Berger JR, Cree BA, Greenberg B, Hemmer B, Ward BJ, Dong VM, et al. Progressive multifocal leukoencephalopathy after fingolimod treatment. Neurology. 2018;90:e1815-e21.

10. Ae R. Prevalence of PML development under fingolimod treatment in Japan. [written in Japanese]. http://prion.umin.jp/file/result_virus2016/ae.pdf. Accessed 18 Apr 2020

11. Nakahara J, Tomaske L, Kume K, Takata T, Kamada M, Deguchi K, et al. Three cases of non-carryover fingolimod-PML: Is the risk in Japan increased? Neurol Neuroimmunol Neuroinflamm. 2019;6:e559.

12. Novartis Japan. Side effect of fingolimod. https://drs-net.novartis.co.jp/ siteassets/common/pdf/gil/ts/ts gil_pms fukusayo_20200331.pdf; https:// drs-net.novartis.co.jp/siteassets/common/pdf/gil/ts/ts_gil_pms_jisshijokyo_2 0200331.pdf. Accessed 18 Apr 2020

13. Sundqvist E, Buck D, Warnke C, Albrecht E, Gieger C, Khademi M, et al. JC polyomavirus infection is strongly controlled by human leucocyte antigen class II variants. PLoS Pathog. 2014;10:e1004084.

14. Dominguez-Mozo Ml, Rus M, Santiago JL, Izquierdo G, Casanova I, Galan V, et al. Study of the anti-JCV antibody levels in a Spanish multiple sclerosis cohort. Eur J Clin Investig. 2017:47:158-66.

15. Weber F, Goldmann C, Krämer M, Kaup FJ, Pickhardt M, Young P, et al. Cellular and humoral immune response in progressive multifocal leukoencephalopathy. Ann Neurol. 2001:49:636-42.

16. Lindå H, von Heijne A, Major EO, Ryschkewitsch C, Berg J, Olsson T, et al. Progressive multifocal leukoencephalopathy after natalizumab monotherapy. N Engl J Med. 2009;361:1081-7.

17. Warnke C, von Geldern G, Markwerth P, Dehmel T, Hoepner R, Gold R, et al. Cerebrospinal fluid JC virus antibody index for diagnosis of natalizumabassociated progressive multifocal leukoencephalopathy. Ann Neurol. 2014; 76:792-801.

18. Ray U, Cinque P, Gerevini S, Longo V, Lazzarin A, Schippling S, et al. JC polyomavirus mutants escape antibody-mediated neutralization. Sci Transl Med. 2015;7:306ra151.

19. Jelcic I, Jelcic I, Kempf C, Largey F, Planas R, Schippling S, et al. Mechanisms of immune escape in central nervous system infection with neurotropic JC virus variant. Ann Neurol. 2016;79:404-18.

20. Jelcic I, Aly L, Binder TM, Jelcic I, Bofill-Mas S, Planas R, et al. T cell epitope mapping of JC polyoma virus-encoded proteome reveals reduced $T$ cell responses in HLA-DRB1*04:01+ donors. J Virol. 2013;87:3393-408. 
21. Egli A, Infanti L, Dumoulin A, Buser A, Samaridis J, Stebler C, et al. Prevalence of polyomavirus BK and JC infection and replication in 400 healthy blood donors. J Infect Dis. 2009;199:837-46.

22. Berger JR, Houff SA, Gurwell J, Vega N, Miller CS, Danaher RJ. JC virus antibody status underestimates infection rates. Ann Neurol. 2013;74:84-90.

23. Berger JR, Miller CS, Danaher RJ, Doyle K, Simon KJ, Norton E, et al. Distribution and quantity of sites of John Cunningham virus persistence in immunologically healthy patients: correlation with John Cunningham virus antibody and urine John Cunningham virus DNA. JAMA Neurol. 2017;74:437-44.

24. Reuwer $A Q$, Heron M, van der Dussen D, Schneider-Hohendorf T, Murk JL. The clinical utility of JC virus antibody index measurements in the context of progressive multifocal leukoencephalopathy. Acta Neurol Scand. 2017; 136(Suppl 201):37-44.

25. Lincoln MR, Montpetit A, Cader MZ, Saarela J, Dyment DA, Tiislar M, et al. A predominant role for the HLA class II region in the association of the $\mathrm{MHC}$ region with multiple sclerosis. Nat Genet. 2005;37:1108-12.

26. Sawcer S, Hellenthal G, Pirinen M, Spencer CC, Patsopoulos NA, Moutsianas $L$, et al. Genetic risk and a primary role for cell-mediated immune mechanisms in multiple sclerosis. Nature. 2011;476:214-9.

27. Yoshimura S, Isobe N, Yonekawa T, Matsushita T, Masaki K, Sato S, et al. Genetic and infectious profiles of Japanese multiple sclerosis patients. PLoS One. 2012;7:e48592.

28. Patsopoulos NA, Barcellos LF, Hintzen RQ, Schaefer C, van Duijn CM, Noble $J A$, et al. Fine-mapping the genetic association of the major histocompatibility complex in multiple sclerosis: HLA and non-HLA effects. PLoS Genet. 2013;9:e1003926.

29. Nakamura $Y$, Matsushita T, Sato S, Niino M, Fukazawa T, Yoshimura S, et al. Latitude and $H L A-D R B 1{ }^{*} 04: 05$ independently influence disease severity in Japanese multiple sclerosis: a cross-sectional study. J Neuroinflammation. 2016;13:239

30. Polman $\mathrm{CH}$, Reingold SC, Banwell B, Clanet M, Cohen JA, Filippi M, et al. Diagnostic criteria for multiple sclerosis: 2010 revisions to the McDonald criteria. Ann Neurol. 2011;69:292-302.

31. Kurtzke JF. Rating neurologic impairment in multiple sclerosis: an expanded disability status scale (EDSS). Neurology. 1983;33:1444-52.

32. Lee P, Plavina T, Castro A, Berman M, Jaiswal D, Rivas S, et al. A secondgeneration ELISA (STRATIFY JCV DxSelect) for detection of JC virus antibodies in human serum and plasma to support progressive multifocal leukoencephalopathy risk stratification. J Clin Virol. 2013;57:141-6.

33. Matsushita T, Matsuoka T, Isobe N, Kawano Y, Minohara M, Shi N, et al. Association of the HLA-DPB1*0501 allele with anti-aquaporin-4 antibody positivity in Japanese patients with idiopathic central nervous system demyelinating disorders. Tissue Antigens. 2009;73:171-6.

34. Gheuens S, Pierone G, Peeters P, Koralnik IJ. Progressive multifocal leukoencephalopathy in individuals with minimal or occult immunosuppression. J Neurol Neurosurg Psychiatry. 2010;81:247-54

35. Gasnault J, Kahraman M, de Goër de Herve MG, Durali D, Delfraissy JF, Taoufik Y. Critical role of JC virus-specific CD4 T-cell responses in preventing progressive multifocal leukoencephalopathy. AIDS. 2003;17:1443-9.

36. Perkins MR, Ryschkewitsch C, Liebner JC, Monaco MC, Himelfarb D, Ireland $\mathrm{S}$, et al. Changes in JC virus-specific T cell responses during natalizumab treatment and in natalizumab-associated progressive multifocal leukoencephalopathy. PLoS Pathog. 2012:8:e1003014.

37. Ballerini C, Guerini FR, Rombola G, Rosati E, Massacesi L, Ferrante P, et al. HLA-multiple sclerosis association in continental Italy and correlation with disease prevalence in Europe. J Neuroimmunol. 2004;150:178-85.

38. George MF, Briggs FB, Shao X, Gianfrancesco MA, Kockum I, Harbo HF, et al. Multiple sclerosis risk loci and disease severity in 7,125 individuals from 10 studies. Neurol Genet. 2016:2:e87.

39. Briggs FBS, Yu JC, Davis MF, Jiangyang J, Fu S, Parrotta E, et al. Multiple sclerosis risk factors contribute to onset heterogeneity. Mult Scler Relat Disord. 2019;28:11-6.

40. EUROSTAM. Allele*frequencies in worldwide populations. http://www. allelefrequencies.net/hla6006a.asp. Accessed 28 Feb 2020.

41. Tanaka M, Kinoshita M, Tanaka K. Anti-John Cunningham virus index in Japanese patients with multiple sclerosis and neuromyelitis optica-related disorder. Clin Exp Neuroimmunol. 2015;6:309-11.

42. Aoyama S, Mori M, Uzawa A, Uchida T, Masuda H, Ohtani R, et al. Serum anti-JCV antibody indexes in Japanese patients with multiple sclerosis: elevations along with fingolimod treatment duration. J Neurol. 2018;265:1145-50
43. Paz SPC, Branco L, Pereira MAC, Spessotto C, Fragoso YD. Systematic review of the published data on the worldwide prevalence of John Cunningham virus in patients with multiple sclerosis and neuromyelitis optica. Epidemiol Health. 2018:40:e2018001.

44. Olsson T, Achiron A, Alfredsson L, Berger T, Brassat D, Chan A, et al. Anti-JC virus antibody prevalence in a multinational multiple sclerosis cohort. Mult Scler. 2013;19:1533-8.

45. Kowarik MC, Pellkofer HL, Cepok S, Korn T, Kumpfel T, Buck D, et al. Differential effects of fingolimod (FTY720) on immune cells in the CSF and blood of patients with MS. Neurology. 2011;76:1214-21.

46. Koralnik IJ, Boden D, Mai VX, Lord Cl, Letvin NL. JC virus DNA load in patients with and without progressive multifocal leukoencephalopathy. Neurology. 1999;52:253-60

47. Rudick RA, O'Connor PW, Polman CH, Goodman AD, Ray SS, Griffith NM, et al. Assessment of JC virus DNA in blood and urine from natalizumabtreated patients. Ann Neurol. 2010;68:304-10.

48. Ogawa K, Okuno T, Hosomichi K, Hosokawa A, Hirata J, Suzuki K, et al. Nextgeneration sequencing identifies contribution of both class I and II HLA genes on susceptibility of multiple sclerosis in Japanese. J Neuroinflammation. 2019;16:162.

49. Piccolo L, Kumar G, Nakashima I, Misu T, Kong Y, Wakerley B, et al. Multiple sclerosis in Japan appears to be a milder disease compared to the UK. J Neurol. 2015;262:831-6.

50. Nakamura Y, Gaetano L, Matsushita T, Anna A, Sprenger T, Radue EW, et al. A comparison of brain magnetic resonance imaging lesions in multiple sclerosis by race with reference to disability progression. J Neuroinflammation. 2018;15:255

\section{Publisher's Note}

Springer Nature remains neutral with regard to jurisdictional claims in published maps and institutional affiliations.
Ready to submit your research? Choose BMC and benefit from:

- fast, convenient online submission

- thorough peer review by experienced researchers in your field

- rapid publication on acceptance

- support for research data, including large and complex data types

- gold Open Access which fosters wider collaboration and increased citations

- maximum visibility for your research: over $100 \mathrm{M}$ website views per year

At BMC, research is always in progress.

Learn more biomedcentral.com/submissions 